\title{
A survey on impact of emotional intelligence, organizational citizenship behaviors and job satisfaction on employees’ performance in Iranian hotel industry
}

\author{
Kambiz Heidarzadeh Hanzaee $^{a}$ and Majid Mirvaisi ${ }^{\mathbf{b}^{*}}$
}

${ }^{a}$ Department of Business Management, Science and Research Branch, Islamic Azad University, Tehran, Iran ${ }^{b}$ Department of Business Management, Neyshabur Branch, Islamic Azad University, Neyshabur, Iran.

\section{H R O N I C L E}

Article history:

Received January 14, 2013

Received in revised format

10 April 2013

Accepted 12 April 2013

Available online

April 142013

Keywords:

Emotional Intelligence (EI)

Job Satisfaction (JS)

Organizational Citizenship

Behavior (OCB)

Employees Performance (EP)

Hotel Industry

\begin{abstract}
A B S T R A C T
The objective of this study is to investigate the effect of employees' Emotional Intelligence (EI), Job Satisfaction (JS) and Organizational Citizenship Behavior (OCB) on Employee's Performance (EP) in Iranian hotel industry. The proposed study of this paper designs a questionnaire and distributes it among 225 employees who have a high interaction with customers in hotel industry. In order to describe the data, the frequency distribution tables have been used and the structural equations model (SEM) has been used to describe the data. The results of this survey have confirmed all the proposed hypotheses of this survey except the one, which was associated with the relationship between OCB on EP. Therefore, EI have positive impacts on JS, OCB and EP in Iranian hotel industry. Conclusion and Managerial implications have been offers.
\end{abstract}

\section{Introduction}

The lifeblood of a service organization is its employees, particularly front-line, customer contact employees. Front-line employees are central in determining service quality as they represent the firm in interactions with customers, which is an important avenue for customer value creation (Bell \& Menguc, 2002). Owing to human interaction in service encounters, management cannot all front-line behaviors, specify (Ackfoldt \& Malhotra, 2013). In service industry, front-line employees have multiple roles to fulfill, and are answerable to demands from line managers and others within the organization, as well as customers. Brackett et al. (2006) focused on the importance of emotions in association with intellectual abilities, particularly in organizations that evaluate employees' abilities in terms of emotions instead of cognition. The importance of emotional intelligence (EI) is

*Corresponding author. Tel: +989155020571

E-mail addresses: mirvaisi@yahoo.com (M. Mirvaisi)

(C) 2013 Growing Science Ltd. All rights reserved. doi: $10.5267 /$ j.msl.2013.04.010 
emphasized because human relations in organizations are influenced by emotional factors more than by rational factors.

According to Druskat and Wolff (2001), the emotional quotient is as important as the intelligence quotient; indeed, the EI of individuals who carry out duties and play essential roles in ensuring organizational outcomes is quite significant. Therefore, successful organizations require employees who can communicate effectively, control their emotions, and demonstrate their technical abilities (Jung \& Yoon, 2011). Furthermore, in service-oriented businesses such as hotels and banking employees are service providers in direct face-to face contact with customers; thus, any EI, which plays important roles in controlling emotions; is more influential. However, studies of hotel employees in association with the effectiveness of EI are very rare. Consequently, for employees to keep emotionally and healthy conditions in service encounters in hotels and continuously create positive outcomes, their ability to control their emotions should be prioritized. Indeed, EI is thus required of employees who must perceive and control their own emotions as well as those of customers in the course of performing their emotional labor. Hence, it is argued that the success or failure of a service encounter is largely determined by the frontline employee EI in service industry especially in hotels.

\section{Literature review}

\subsection{Emotional Intelligence (EI)}

The phrase EI was first used by Payne (1985) and was considered to indicate a person's ability to “ relate to fear, pain and desire". According to Salovey and Mayer (1990), EI is the ability to examine individual's feelings and emotions, to differentiate among them, and to use this as reference to one's thinking and actions (Hsu et al., 2012). In professional settings, Singh, (2001) argued that EI facilitates the managers and employees to identify and realize emotions and implement it to manage oneself and their relationship with others. This shows the importance of EI for effectively managing the job. Goleman (1995) identified four dimensions of EI including self-awareness knows one's internal states, preferences, resources, and intuitions.

Self awareness is to identify one's weaknesses and strengths (Shahzad et al., 2011) and it is a management of one's internal states, impulses, and resources to facilitate reaching goals, it is also considered as managing one's own disciple and values. Individuals' control over their disciple helps to cope with anger and stress (Rahim et al., 2002). Social awareness being aware of others' feelings, needs, and concerns, social awareness is to know about socially desirable behaviors (Goleman, 1998). Relationship management includes helping others develop, inspirational leadership, influence, communication, catalyzing change, conflict management, fostering collaboration and teamwork.

\subsection{Organizational Citizenship Behavior (OCB)}

Smith et al. (1983) introduced the notion of OCB defining it as discretionary behavior, which goes beyond ones' official role and it is intended to help other people in the organizational or to show conscientiousness and support toward the organization (Yilmaz \& Tasdan, 2009). OCB is "the maintenance and enhancement of the social and psychological context that supports task performance" (Organ, 1997).

\subsection{Job Satisfaction (JS)}

JS has been defined in various complimentary ways. According to Spector (1985, p. 693) JS is "employee attitudes, including pay, promotion, supervision, fringe benefits, contingent rewards, operating procedures, coworkers, nature of work, and communication" (Anari, 2012). Locke (1976) 
defines JS “a pleasurable or positive emotion state results from the appraisal of ones' job or job experience" (Hassan \& Hashim, 2011).

\subsection{Employees Performance (EP)}

Huselid (1995) found that human resource practices influence various aspects of organizational performance, including turnover, productivity, and corporate financial performance. Lai and Cheng (2005) considered perceived market performance and productivity performance as an important index of organizational performance. Furthermore, Guest et al. (2004) perceived organizational performance outcomes as management rating of EP, employees' innovation, and employment relations.

\section{Research Hypotheses \& Conceptual model}

H1: EI is positively associated with EP.

H2: EI is positively associated with JS.

H3: EI is positively associated with OCB.

H4: JS is positively associated to OCB.

H5: JS is positively associated to EP.

H6: OCB is positively associated to EP.

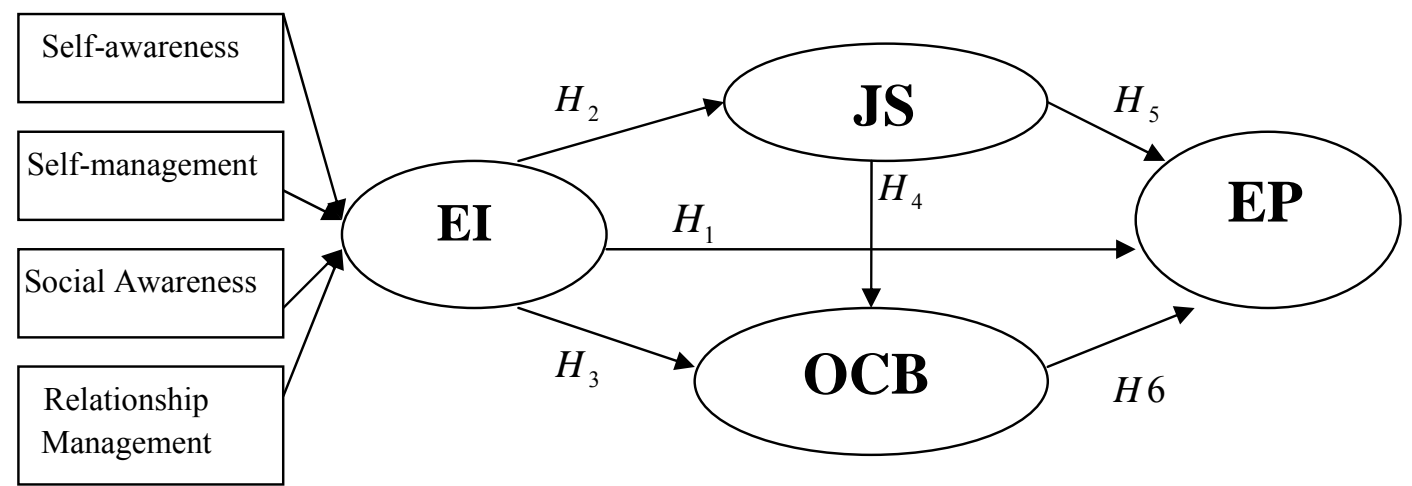

Fig. 1. Proposed Research Model

\section{Methodology}

\subsection{Data Collection and Sample}

The data collection was accomplished through onsite administration of a survey among employees who were working for some hotels in Iran. The participants were randomly sampled across various departments and ranks. The reason of simple random sampling technique for data collection was that it was difficult to select the data from only a one specified sector. Thus, the design of study is cross sectional. Total 235 questionnaires were distributed. Out of 235, only 225 usable responses were received. 


\subsection{Location (Statistical population) and time of research}

The statistic group for this research has been the employees of service industry in Khorasan-e Razavi, Khorasan-e Shomali and Khorasan-e Janoobi provinces of Iran and a number of 235 employees who were face to face by customers in the most of the time when working in hotel. The concerned group has been selected as it has got the highest interaction with the customers. The initial studies and the period of conducting this research has been in a time span of 4 months by the end of March 2013 through.

\subsection{Sampling method and determining the samples size}

Considering the features of the current research, the sampling method applied for this research has been the probable type, conducted in two phases. In the first phase, the simple random sampling has been used to choose the hotels and in phase two the single-stage cluster sampling has been used in factor analysis; the data from the statistic group and the number of samples are of special significance. Bringing into attention the time and the costs limits as well as the above introduction, the number of samples in all hotels of in the three provinces has been 220 items.

\subsection{Methods and instruments applied for data gathering}

Researchers contacted managers of hotel at three provinces in Iran. Because of this contact, various departmental managers in these hotels agreed to participate in our study. A total of 235 questionnaires were prepared and distributed to frontline employees in these hotels based on the information of participating organizations. Participants were assured of the confidentiality of the data. By the cut-off date for inclusion, 220 usable responses were collected. The questionnaire were shaped in three stages, first demographics characteristic, second by the questions for measurement of variable and at end and finally, an open question for gathering employees suggestions about the research. Of the respondents 52 percent $(n=115)$ were female and 36 percent of them $(n=80)$ were married. The subject ranged in age from 20-54 with a mean age of 32 years old. On average, the subjects possessed 6.6 years of hotel experience and 4.6 years in the current organization.

\subsection{Measurement of variables \& analysis of data}

As will be detailed in this section, the constructs examined in this study were mainly operationalized using scales found in extant literature. The survey mechanism was first prepared in English and then translated into Persian using a back-translation procedure. The Persian version of the survey was pilot tested on 20 employees of hotel in Mashhad, Birjand and Bojnourd and then consultant by service expert in hoteling industry of Iran. According to the results of this pilot study, the 20 employees of hotel did not have any difficulty understanding the survey items. Hence, the instrument was deemed ready for the main study. All the variables are measure by five-point scales Likert, ranging from $1=$ "strongly disagree" to $5=$ "strongly agree" in the questionnaire. Structural equation modeling (SEM) was employed to examine the hypothesized relationships in the proposed model.

\section{Table 1}

Mean, Standard deviations, Correlations among Constructs \& Cronbach alpha

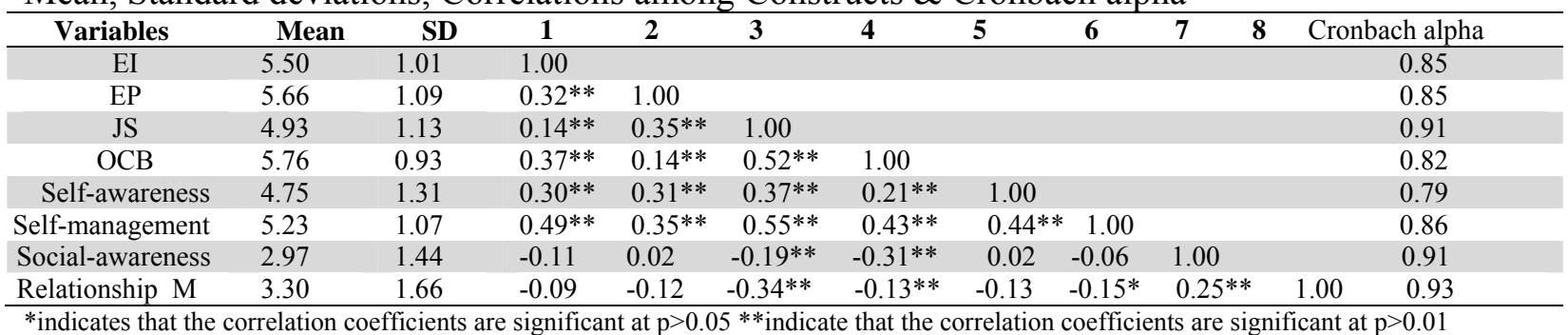




\section{Results}

The measurement model was first examined to validate the research constructs. To assess the overall fit of the model, Chi-Squared statistic $\left(\chi^{2}\right)$, root mean square error of approximation (RMSEA), the non-normed fit index (NNFI), and comparative fit index (CFI) were employed (Hu \& Bentler, 1998, 1999). Generally, RMSEA value at or below 0.08 demonstrates good fit (Brown \& Cudeck, 1989). NNFI and CFI values of at least 0.90 indicate an acceptable level of good fit. The measurement model of this study demonstrated overall a high degree of good fit to the data, $\chi 2=265.66, \mathrm{df}=126$, $\mathrm{RMSEA}=0.077, \mathrm{NNFI}=0.94$, and $\mathrm{CFI}=0.95$.

All measurement scales showed statistically significant loading on their corresponding constructs at the alpha level of 0.001 . Discriminate and convergent validity were also considered to be ensured since the average variance extracted (AVE) of all constructs were greater than the squared correlation between constructs and exceeded minimum criterion of 0.50 (Fornell \& Larcker, 1981). As a next step, the proposed model and causal relationships of variables were examined through a structural model analysis. The proposed model of this study indicated overall a high degree of good fit to the data, $\chi 2=248: 47$, df $=176$, RMSEA $=0.046$, NNFI $=0.98$, and CFI $=0.98$ and, hypothesis-testing results are summarized in Table 2. H1 predicted that a hotel worker's EI would positively influence his/her EP. In the model, this prediction received full support ( $\mathrm{t}=3: 50 ; \mathrm{p}<0: 001)$; thus, H1 is supported. Next, $\mathrm{H} 2$ predicted that EI had a positive influence on JS hotel worker.

As we can observe from the results of Table 2, this prediction also received statistical support $(\mathrm{t}=5: 17 ; \mathrm{p}<0: 001)$; hence, $\mathrm{H} 2$ is supported. Similarly, H3 posited that EI has a positive effect on OCB hotel worker. In the model, this prediction received full support $(t=4: 47 ; p<0: 001)$; therefore, H3 is supported. H4 posited that a worker's level of JS has a positive influence on his/her OCB. Our findings indicate that JS has a significant positive influence on OCB $(\mathrm{t}=2: 91 ; \mathrm{p}<0: 01)$; thus, H4 is supported. Our model then hypothesized a positive causal path between JS and EP (H5); this path was supported by our data $(\mathrm{t}=3: 00 ; \mathrm{p}<0: 01)$; H5 is, therefore, supported. Next, this research predicted that OCB has a positive influence on EP (H6). This hypnosis did not receive statistically significant support; consequently, it can be concluded that H6 is not supported.

Table 2

Results of the Proposed Model

\begin{tabular}{lccc}
\hline Hypothesized Path & Standard Path Coefficient & T-Value & Hypotheses Testing \\
\hline $\mathrm{H} 1:$ EI $\rightarrow$ EP & 0.25 & $3.50^{* *}$ & Supported \\
H2: EI $\rightarrow$ JS & 0.37 & $5.17^{* *}$ & Supported \\
H3: EI $\rightarrow$ OCB & 0.36 & $4.47^{* *}$ & Supported \\
H4: JS $\rightarrow$ OCB & 0.21 & $2.91^{*}$ & Supported \\
H5: JS $\rightarrow$ EP & 0.46 & $3.00^{*}$ & Supported \\
H6: OCB $\rightarrow$ EP & -0.04 & -0.29 & Not Supported \\
H1: EI $\rightarrow$ EP & 0.25 & $3.50^{* *}$ & Supported \\
\hline Note: ${ }^{*}<0.01,{ }^{* *} \mathrm{p}<0.001$ & & &
\end{tabular}

\section{Conclusion}

This study examined the effect of EI dimension on JS, OCB and EP. EI has been categorized into four areas including self-awareness, self-management, social awareness and relationship management. In addition, this study found that this dimension had significant impact on the EP in hotel industry in Iran. The results of the current study demonstrated that EI helps understand one's emotions effectively while using and controlling emotions would induce voluntary and positive behaviors. In particular, EI in the use of emotion and self-emotion appraisal was more important in increasing OCB; moreover, use of emotion had a greater influence on OCB than self-emotion 
appraisal had. This result confirms that, if employees understand, control, and use their emotions effectively, they will create positive working environments and significantly improve organizational outcomes such as increased OCB.

In addition, if employees of hoteling industry have high EI, they will be able to balance work with organization demands in order to minimize work conflicts. Therefore, counseling and personnel psychologists should be used by various organizations where employee staff and the employees have a significant role in offering service and customer satisfaction. Because of that, EI has a maximum role in providing attractive and conductive working environments, which would motivate the employees and enhance their JS and satisfaction to their career and organizations. In addition, if employees of service hoteling industry have a high EI, they will have an output like high level of innovation, productivity, employee relation, empathy by customer and financial performance in service industry and employees EI have a critical role in enhancing EP on various departments like marketing and accounting.

\section{Implication of the research}

In terms of theory building, this study contributes to existing business literature. First, from a theoretical perspective, a number of past studies have analyzed the impact of EI on EP, EI on OCB, JS on EP, but we were the first to examine this association in a hotel context, which is a work environment and front line employees have significant role in customer satisfaction and retention. Emotionally intelligence individuals may also be more likely to remain in EP in which they are satisfied; this contention may also support the linkage between EI and EP. Again, due to the high human components that characterize the hotel business, this casual connection between EI, OCB, JS and EP is the one that must be well understood by those manager and making decisions in the service sector, which have high interaction by customer like hotels. Therefore, it would be informative for future research to investigate potentially intervening factors in the components of this conceptual model in the hotel industry.

This study focused on the hotel industry because hotels are labor intensive and hospitality oriented in order to provide personal service to customers and they are particularly required to manage their EI was a very important factor in management of human resource in organizations. The EI of hotel employees should be managed with to ensure improved business outcomes. Training employees' EI will improve service quality and improvement over the long term. Although they provide useful managerial implications, our researches are subject to certain limitations. One shortcoming of this study, for example, is that it operationalized the exercise construct by gathering exercise frequency data, but did not consider exercise intensity.

Along these same lines, a related shortcoming is that all data are self-reported. Furthermore, since the finding derive from Iranian hotel worker sample; caution should be exercised in generalizing these results to other setting and populations. These limitations of this study can be served as suggestions for future research because these current study only beings to shed light on the valuable information yet to be known regarding the affective outcomes of exercise in a service context.

\section{Acknowledgment}

The authors would like to thank the employees of different hotels for cordially participating in this survey. We are grateful for the comments on earlier version of this work, which has significantly contributed to the quality of the paper. 


\section{References}

Ackfeldt, A.L. \& Neeru Malhotra, N. (2013). Revisiting the role stress-commitment relationship. Can managerial interventions help? European Journal of Marketing, 47(3/4), 353-374.

Anari, N.N. (2012). Teachers: Emotional intelligence, job satisfaction, and organizational commitment. Journal of workplace Learning, 24, (4), 256-269.

Bell, S.J. \& Menguc, B. (2002). The employee-organization relationship, organizational citizenship behaviors, an Organizational Citizenship Behavior d superior quality. Journal of Retailing, 78 (2), $131-46$.

Brackett, M.A., Rivers, S.E., Shiffman, S., Lerner, N., \& Salovey, P. (2006). Relating emotional abilities to social functioning: a comparison of self-report and performance measures of emotional intelligence. Journal of Personality and Social Psychology, 91(4), 780-795.

Brown, M.W. \& Cudeck, R. (1989). Single sample cross-validation indices for covariance structures. Multivariate Behavioral Research, (24), 445-55.

Druskat, V.U., \& Wolff, S.B., (2001). Building the emotional intelligence of groups. Harvard Business Review, 79 (3), 80-90.

Fornell, C. \& Larcker, D. (1981). Structural equation models with unobservable variables and measurement error. Journal of Marketing Research, 18(1), 39-50.

Hassan, A. \& Hashim, J. (2011). Role of organizational justice in determining work outcomes of national and expatriate academic staff in Malaysia. International Journal of Commerce and Management, 21 (1), 82-93.

Hu, L. \& Bentler, P.M. (1999). Cutoff criteria for fit indexes in covariance structure analysis: conventional criteria versus new alternatives. Structural Equation Modeling, 6, 1-55.

Huselid, M. A. (1995). The Impact of Human Resource Management Practices on Turnover, Productivity, and Corporate Financial Performance. Academy of Management Journal, 38(3), 635672.

Jung, H. S., \& Yoon, H. H. (2012). The effects of emotional intelligence on counterproductive work behaviors and organizational citizen behaviors among food and beverage employees in a deluxe hotel. International Journal of Hospitality Management, 31(2), 369-378.

Lai, K. H., \& Cheng, T. C. E. (2005). Effects of quality management and marketing on organisational performance. Journal of Business Research, 58, 446-456.

Locke, E. (1976). The nature and consequent of job satisfaction. in Dunette, M.D. (ed), Handbook of Industrial and Organizational Psychology, Rand-McNally, Chicago, IL, 1297-349.

Goleman, D. (1998). Working with emotional intelligence. New York: Bantam Books.

Goleman, D., (1995). Emotional intelligence: Why it can matter more than IQ. New York: Bantam.

Guest, D., Conway, N., \& Dewe, P. (2004). Using sequential tree analysis to search for 'bundles' of HR practices. Human Resource Management Journal, 14(1), 79-96.

Organ, D.W. (1988). A restatement of the satisfaction performance hypothesis. Journal of Management, 14 (4), 547-557.

Organ, D.W. (1997). Organizational citizenship behavior: it's construct clean-up time. Human Performance, 10 (2), 85-97.

Payne W. L. (1985). A study of emotion: developing emotional self-integration; relating intelligence; to fear, pain and desire (theory, structure of reality, problem-solving, contraction expansion, tuning in/coming out/letting go). Doctoral Dissertation, the Union for Experimenting Colleges and Universities.

Rahim, M. A. et al. (2002). A model of emotional intelligence and conflict management strategies: a study in seven countries. International Journal of Organizational Analysis, 10(4), 302-326.

Salovey, P., \& Mayer, J.D. (1990). Emotional Intelligence. Imagination Cognit. Pers, 9, 185211.

Singh, D. (2001). Emotional Intelligence at Work. ${ }^{\text {st }}$ ed., New Delhi: Response Books. (Chapter 2).

Shahzad, K., Sarmad, M., \& Abbas, M. (2011). Impact of Emotional Intelligence (EI) on employee's performance in telecom sector of Pakistan. Journal of Business, 5(4), 1225-1231. 
Smith, C.A., Organ, D.W. \& Near, J.P. (1983). Organizational citizenship behavior: its nature and antecedents. Journal of Applied Psychology, 68, (44), 653-663

Spector, P.E. (1985). Measurement of human service staff satisfaction: Development of the job satisfaction survey. American Journal of Community Psychology, 13 (6), 693-713.

Yuan, B. J., Hsu, W. L., Shieh, J. H., \& Li, K. P. (2012). Increasing emotional intelligence of employees: Evidence from research and development teams in Taiwan. Social Behavior and Personality: An international journal, 40(10), 1713-1724.

Yilmaz, K. \& Tasdan, M. (2009). Organizational citizenship and organizational justice in Turkish primary schools. Journal of Educational Administration, 47 (1), 108-126. 